\title{
ARE REAL INTEREST RATES EQUAL ACROSS COUNTRIES? \\ AN EMPIRICAL INVESTIGATION OF INTERNATIONAL \\ PARITY CONDITIONS
}

Frederic S. Mishkin

Working Paper No. 1048

NATIONAL BUREAU OF ECONOMIC RESEARCH 1050 Massachusetts Avenue

Cambridge MA 02138

December 1982

I thank for their helpful comments: Robert Cumby, Thomas Doan, Robert Gordon, Fumio Hayashi, Craig Hakkio, Marjorie McElroy, Michael Mussa, Michael Parkin and the participants in workshops at the University of Liverpool Seminar in Open Econom Macroeconomics, the Board of Governors of the Federal Reserve, the University of Illinois, Champaign-Urbana, Northwestern University and the University of Western Ontario. The National Science Foundation and the Sloan Foundation have provided research support. The research reported here is part of the NBER's research program in Economic Fluctuations. Any opinions expressed are those of the author and not those of the National Bureau of Economic Research. 
Are Real Interest Rates Equal Across

Countries? An Empirical Investigation of

International Parity Conditions

ABSTRACT

The proposition that real rates are equal across countries is worth studying because it is central to our understanding of open economy macroeconomics and because it is also an important issue to policy makers. If it is true, then domestic monetary authorities have no control over their real rate relative to the world rate, limiting the impact of their stabilization policies. In addition, as Feldstein has pointed out, unless real rates can differ across countries, policies directed at increasing domestic savings cannot increase the rate of capital formation and hence productivity. The equality of real rates is also worth investigating, because it is intimately linked to and provides information on the basic parity conditions featured so prominently in open economy macro models.

This paper conducts empirical tests of the equality of real rates and other parity conditions across countries using euro rate data over the 1967-II to 1979-II sample period. The empirical evidence strongly rejects the hypothesis of the equality of real euro rates across countries. The joint hypotheses of uncovered interest parity and ex ante relative PPP, or the unbiasedness of forward rate forecasts and ex ante relative PPP, are also strongly rejected. Yet independent tests of uncovered interest parity, the unbiasedness of forward rate forecasts and ex ante relative PPP yield few rejections and high marginal significance levels. The evidence suggests that it is worth studying open economy models which allow: 1) domestic real rates to differ from world rates, 2) time varying risk premiums in the forward market or 3) deviations from ex ante relative purchasing power parity. The evidence also leaves open the possibility for policy makers to exert some control over their domestic real rate relative to those in the rest of the world. However, the evidence does not rule out that there is a tendency for real rates across countries to equalize over time, and this is an important topic for further research.

Frederic S. Mishkin

Department of Economics

Northwestern University

Evanston, Illinois 60201

(312) $492-5690$ 


\section{Introduction}

The relationship of real interest rates across countries is of central importance to our understanding of open economy macroeconomics. In models where there is costless international arbitrage in goods and financial assets, real interest rates for comparable securities should be equal across countries. This has been a feature of much of the early research in the monetary approach to exchange rates: e.g. Frenkel (1976) and Bilson (1978). However, more recent theoretical models in the exchange rate literature, such as Dornbusch (1976), Frenkal (1979) and Mussa (1982), depend on differing real rates between countries in the short-run.

The proposition that real rates are equal across countries is worth studying because it sheds light on these theoretical models and because it is also an important issue to policy makers. If it is true, then domestic monetary authorities have no control over their real rate relative to the world rate, limiting the impact of their stabilization policies. In addition, as Feldstein (1982) has pointed out, unless real rates can differ across countries, policies directed at increasing domestic savings cannot increase the rate of capital formation and hence productivity. We shall also see that the equality of real rates is also worth investigating, because it is intimately linked to and provides information on the basic parity conditions featured so prominently in open economy macro models.

This paper conducts empirical tests of the equality of real rates across countries using euro rate data over the 1967-II to 1979-II sample period. The next section develops the methodology of the tests. It is then followed by a discussion of the data and the empirical results. The final section summarizes the empirical evidence and provides some concluding remarks. 
Each country's real rate of interest for one period euro bonds is defined from the Fisher (1930) equation

(1) $1_{t} \equiv r r_{t}+\pi_{t}^{e}$

where

$$
\begin{aligned}
i_{t}= & \text { The nominal interest rate earned on a one period bond denominated } \\
& \text { in that country's currency, at time } t-i \text {.e. it is the nominal } \\
& \text { return for holding the one-period bond from } t-1 \text { to } t, \\
\pi_{t}^{e}= & \text { the country's rate of inflation from } t-1 \text { to } t \text { expected at } \\
& \text { time } t-1, \\
r r_{t}= & \text { the one-period real rate of interest. }
\end{aligned}
$$

$\overline{1}$ Note that this definition of a country's real rate matches up the euro security denominated in its currency with its inflation rate. Clearly, a domestic resident might be interested in the real rate obtained by purchasing a euro security denominated in a foreign currency. However, given that uncovered interest parity holds, in this case he will earn the same real return. As will become obvious in the next section, uncovered interest parity is intimately related to the equality of real rates across countries and thus it is only necessary to test the equality of real rates using the definition above. 
Hence, the real interest rate, $r r_{t}$, is just the difference between the nominal interest rate and the, expected inflation rate: ${ }^{2}$ it is the real return from holding the one-period euro bond from $t-1$ to $t$ which is expected at time $t-1$. Because the real rate is a return expected at the beginning of the period, it is also frequently referred to as the ex ante real rate. The more precise terminology is used to differentiate it from the ex post real rate, namely, the actual real return from holding the oneperiod euro bond from $t-1$ to $t$. It equals the nominal interest rate minus the actual inflation rate from $t-1$ to $t$ and can be written as

(2) $\quad$ eprr $r_{t}=i_{t}-\pi_{t} \equiv r r_{t}-\left(\pi_{t}-\pi_{t}^{e}\right)=r r_{t}-\varepsilon_{t}$

where

eprrr $_{t}=$ the one-period ex post real rate for the euro bond maturing at time $t$,

$\pi_{t}=$ the actual inflation rate from $t-1$ to $t$,

$\varepsilon_{t}=\pi_{t}-\pi_{t}^{e}=$ the forecast error of inflation.

Note that for expositional convenience, the ex ante real rate is always referred to as the real rate throughout this paper, while the ex post real rate always refers to the variable defined in equation (2).

The critical assumption behind the methodology developed here is the rationality of inflation expectations in the euro bond market, which yields the condition

\footnotetext{
${ }^{2} \mathrm{All}$ returns, inflation and interest rates in the empirical work are continuously compounded so that the usual additional second order term is not necessary in the Fisher equation (1). Note that if holding period returns are used in the empirical work here rather than continuously compounded returns, there is almost no change in the results.
} 
(3)

$$
\pi_{t}^{e}=E\left(\pi_{t} \mid \phi_{t-1}\right)
$$

where

$$
\phi_{t-1}=\text { all available information at time } t-1 \text {, }
$$

which in turn implies

$$
E\left(\pi_{t}-\pi_{t}^{e} \mid \phi_{t-1}\right)=E\left(\varepsilon_{t} \mid \phi_{t-1}\right)=0
$$

This assumption for financial markets is firmly grounded both theoretically and empirically, and it is all that is required to derive the proposition which is the basis of the empirical tests to follow. Consider the linear least squares projection of the real rate on an information set $x_{t-1}$ contained in $\phi_{t-1}$.

$$
P\left(\operatorname{rr}_{t} \mid x_{t-1}\right)=x_{t-1}^{\beta}
$$

Proposition 1: If the expectations of inflation are rational, then the linear least squares projection of the ex post real rate on any information set $x_{t-1}$ available at time $t-1$ equals the linear least squares projection of the ex ante real rate on the same information set: i.e.

$$
P\left(\operatorname{eprr}_{t} \mid x_{t-1}\right)=P\left(r r_{t} \mid x_{t-1}\right)
$$

where $P\left(\cdots \mid x_{t-1}\right)=$ the linear least squares projection operator on $x_{t-1^{\circ}}$. Proof:

From the definition of the ex post real rate

$$
P\left(\text { eprr }{ }_{t} \mid x_{t-1}\right)=P\left(r_{t} \mid x_{t-1}\right)-P\left(\varepsilon_{t} \mid x_{t-1}\right)
$$

and by the law of iterated projections

$$
P\left(\varepsilon_{t} \mid x_{t-1}\right)=P\left(P\left(\varepsilon_{t} \mid \phi_{t-1}\right) \mid x_{t-1}\right)
$$


The rationality assumption in (4) implies that $P\left(\varepsilon_{t} \mid \phi_{t-1}\right)=0$ and hence $P\left(\varepsilon_{t} \mid X_{t-1}\right)=$ O. Q.E.D.

Using a superscript to denote a particular country's varlables, the null hypothesis of the equality of real rates across countries is

$$
r r_{t}^{i}=r r_{t}^{j} \text { for all countries } i \text { and } j \text {. }
$$

and hence

$$
P\left(\operatorname{rr}_{t}^{i} \mid x_{t-1}\right)=P\left(r_{t}^{j} \mid x_{t-1}\right)
$$

Using Proposition 1, this null hypothesis implies

$$
P\left(\operatorname{eprr}_{t}^{i} \mid X_{t-1}\right)=X_{t-1} \beta^{i}=P\left(\operatorname{eprr}_{t}^{j} \mid x_{t-1}\right)=X_{t-1} \beta^{j} .
$$

This condition indicates that, when each country's ex post real rate is projected against the same information set known at $t-1$, then

$$
\beta^{j}-\beta^{1}=0
$$

for a11 $i$ and $j$.

With $m$ countries, even though there are $\frac{\mathfrak{m}(\mathrm{m}-1)}{2}$ of the constraints, only m-1 of them are independent. The test of the null hypothesis of real rate equality for all countries is obtained by jointly testing $b^{j}=0$ in the m - 1 ordinary least squares (OLS) regressions

$$
\operatorname{eprr}_{t}^{j}-\operatorname{eprr}_{t}^{1}=x_{t-1} b^{j}+u_{t}^{j} \quad j=2, \ldots, m
$$

where

$$
\begin{aligned}
b^{j}= & \beta^{j}-\beta^{1} \\
u_{t}^{j}= & \varepsilon_{t}^{i}-\varepsilon_{t}^{j} \text { under the null hypothesis, which is the forecast } \\
& \text { error of the inflation differential - which has the property } \\
& \text { that } E\left(u_{t}^{j} \mid \phi_{t-1}\right)=0 \text { and hence } u_{t}^{j} \text { will be serially uncorrelated }
\end{aligned}
$$


under the nu11. 3

One pitfall to beware is that these joint tests cannot be conducted by estimating each country's OLS constrained and unconstrained regressions separately, adding up their sum of squares, and then carrying out the usual comparison to construct the F-test. ${ }^{4}$ This yields incorrect test statistics because the covariance of the OLS parameter estimates in different equations is assumed to be zero. Instead the correct variance-covariance matrix of the stacked OLS parameter estimates is

\footnotetext{
${ }^{3}$ Combining the null hypothesis of (9) with the definition of the ex post real rate in (2) yields the definition above and the rationality of inflation forecasts assumed in (4) then leads to the serial uncorrelatedness property. The parameters and their variance covariance matrices will be consistently estimated with OLS under the null so that test statistics will have the appropriate asymptotic distributions. However, if the null is false, then $u_{t}$ could be serially correlated and then the power of the test might not be high. Thus, if there is a failure to reject the null, we would want to be sure that this is not the result of serial correlation in the $u_{t}^{j}$. There are three countries that display significant first order correlation in the equation (12) regressions using WPI data (Durbin-Watson of 1.03 to 1.36 ), but first order serial correlation is not present when the CPI data are used. In any case, strong rejections of the null hypothesis of the real rates arise for both and CPI and WPI regressions. In the regression tests of uncovered interest parity, the unbiasedness of the forward rate and the PPP condition, no evidence of first order serial correlation is found.

${ }^{4}$ This statistic is identical to that produced by a seemingly unrelated regression package, because when all the explanatory variables are the same in each equation GLS will generate the same parameter estimates as OLS on each equation.
} 


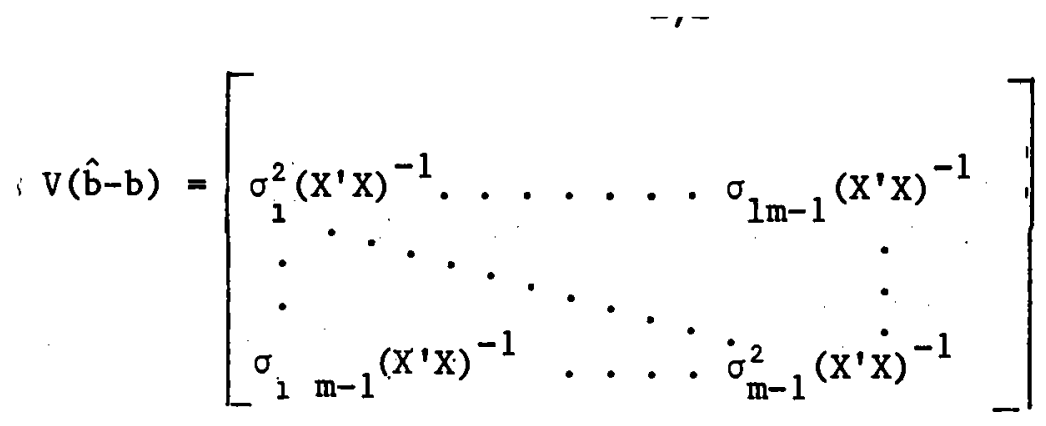

where

$$
\begin{aligned}
& x=\text { the } n \times k \text { matrix of the } x_{t-1} \begin{array}{r}
\left(n=\begin{array}{r}
\text { number of observations for each } \\
\text { regression }
\end{array}\right. \\
\left.k=\text { the number of variables } x_{t-1}\right)
\end{array} \\
& \sigma_{1 j}=\operatorname{cov}\left(u_{t}^{j}, u_{t}^{1}\right) \\
& \sigma_{1}^{2}=\operatorname{cov}\left(u_{t}^{i}, u_{t}^{i}\right)
\end{aligned}
$$

The $F(q,(m-1)(n-k))$ statistic testing $b^{j}=0$ for $j=2, \ldots m$ is then

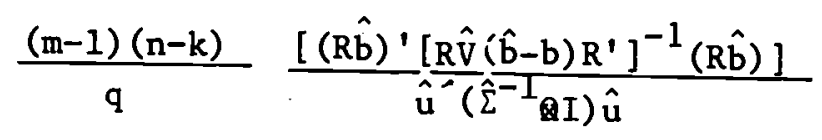

where

$q=$ the number of restrictions tested which are written as $\mathrm{Rb}=0$

$\hat{\Sigma}=$ the variance covariance matrix of the stacked $\hat{u}$

There are two final points that need to be made about this test procedure. Given the rationality of expectations, the condition (11) has been shown to be true for any set of variables $x_{t-1}$ that is contained in the available information set $\phi_{t-1}$. Even if information relevant to the determination of real rates in different countries is excluded from $x_{t-1}$, the condition in (11) and test procedure described here is valid; that is a rejection of the null hypothesis is indeed a rejection of the equality of real rates across countries. That the test procedure is valid even when relevant information is ignored is a common feature of rational expectations tests. (See Abel and Mishkin (1983)). 
However, as condition (11) makes clear, in order to obtain tests with some statistical power, the information set $\mathrm{x}_{t-1}$ must be chosen so that it has significant explanatory power in ex post real rate regressions for these countries. A companion piece to this paper, Mishkin (1982), finds that one information set that does meet this criterion is a fourth order polynomial in time, represented by a constant term and the four variables TIME, TIME $^{2}$, TIME $^{3}$ and TIME $^{4}$. The fourth order polynomial in time should be thought of as a proxy for the smoothly moving (low frequency) component of economic variables that are related to real rates. For example, if the real rate projection for each country against all available information is,

$$
P\left(\left.\operatorname{rr}_{t}^{i}\right|_{t-1}\right)=x_{t-1}^{E} \beta^{i}
$$

and

$$
P\left(X_{t-1}^{E} \mid T_{t-1}\right)=T_{t-1} \theta
$$

where

$$
\begin{aligned}
& \mathrm{x}_{t-1}^{\mathrm{E}}=\text { vector of the economic variables at time } t-1 \\
& \mathrm{~T}_{t-1}=\text { vector of the constant term and the four time variables. }
\end{aligned}
$$

then

$$
\operatorname{eprr}_{t}^{j}-\operatorname{eprr}_{t}^{1}=T_{t-1} \theta\left(\beta^{j}-\beta^{1}\right)+u_{t}+\varepsilon_{t}^{1}-\varepsilon_{t}^{j} \quad j=2, \ldots m
$$

where

$$
u_{t}=r r_{t}^{j}-r r_{t}^{1}-P\left(r r_{t}^{j}-r r_{t}^{1} \mid T_{t-1}\right)
$$


The null hypothesis of $\operatorname{rr}_{t}^{j}=\operatorname{rr}_{t}^{i}$ and hence $\beta^{j}-\beta^{1}=0$ implies that $\theta\left(\beta^{j}-\beta^{1}\right)=0$. Also $u_{t}$ will be zero under the null and the remaining error term will be orthogonal to $\mathrm{T}_{\mathrm{t}-1}$ because of the rationality of inflation expectations.

There are several advantages to using the time variables in the test procedure here. The first is that it can lead to tests of higher power. In Mishkin (1982), four lags of inflation, the lagged money growth and the nominal euro rate for each country are the economic explanatory variables in the ex post real rate regressions for each country. In order to conduct the joint test of real rate equality described here, all these variables for every country -that is, thirty-six of them -- would need to be included in the equation (12) regressions in addition to the constant term. Since there are only forty-nine observations, this leaves us with few degrees of freedom per regression and and the total number of constraints to be tested would be a very large number, over 200. Obviously, we would expect this test to have very little statistical power. The test with the time trend variables involves only five variables per regression, and only a total of 30 constraints to be tested. ${ }^{5}$ Because Mishkin (1982) finds significant explanatory power of the time variables -- in fact in the WPI case they are more significant than the economic variables listed above, --

\footnotetext{
${ }^{5}$ In the tests with the economic variables, there would be only 12 degrees of freedom per regression, 72 in total, with 222 constraints to be tested; while for the tests with the time variables there will be 44 degrees of freedom per regression, 264 in total, with 30 constraints to be tested.
} 
we would expect the time variables test to have greater statistical power. A second advantage of the time variables is that they do not require knowledge of the relevant economic variables to conduct the test. Thus, they may pick up effects of relevant economic variables that the econometrician has inadvertently ignored. In addition, they will only pick

up low frequency deviations from real rate equality. Since low frequency deviations are potentially most important to investment and consumption decisions, these are probably of greatest interest to economists. 


\section{The Empirical Results}

THE DATA

Obviously, there is no unique real interest rate. The magnitude of a real rate depends not only on the risk characteristics of the security being studied, but also on the price index used to calculate real returns. What is the appropriate price index depends on what economic decision is being analyzed. For example, if we are interested in the savings-consumption decision, a price index based on a commodity bundle of consumption goods, such as the CPI, is appropriate. If, on the other hand, we are interested in decisions to trade among countries, then a price index with tradable goods a larger proportion of its commodity bundle, such as the WPI, is more appropriate.

This study analyzes real interest rates in the euro deposit market in the 1967-II to 1979-II period for the following OECD countries: the United States, Canada, the United Kingdom, France, West Germany, the Netherlands, and Switzerland. Quarterly data on three-month euro rates obtained from the Harris Bank tape are used in this study. 6

Euro deposits denominated in different countries' currencies are offshore securities issued by the same bank and therefore have similar default risk. Hence a comparison of real euro rates across countries will not have to be adjusted for differing default risks or non-comparability

\footnotetext{
${ }^{6}$ Only seven of the ten countries' data available in the tape are used here because three of the countries--Italy, Belgium and Japan--either had a high proportion of the data missing or did not satisfy interest parity because of two-tiered exchange rates. In the few cases where Euro rate data were missing for the seven countries, the Euro rate was calculated from the interest parity condition. The rest of the data were checked by verifying that there were no large deviations from interest parity. Several obvious errors in the tape were found in this manner and were corrected.
} 
because of capital market controls. Quarterly data on three-month rates have the advantage that the data are non-overlapping and timing problems that would arise with monthly data are avolded. ${ }^{7}$ The dating convention is as follows. The ex post real rate for a quarter is the actual real return on a three-month bill held from the beginning to the end of that quarter, continuously compounded. Both the CPI and WPI are used in the empirical analysis to calculate inflation rates for the reasons discussed above. Spot and forward exchange rate data were obtained from the Harris Bank tape maintained at the University of Chicago, and the CPI and WPI data were obtained from the International Financial Statistics (IFS) tape maintained by the International Monetary Fund.

THE RESULTS

The tests conducted in Table 1 verify whether the coefficient estimates in the ex post real rate regressions are equalized in all seven OECD countries jointly. Line 1.1 of Table 1 conducts a test for the equality of the mean real rates by only including the constant term in the information set $x_{t-1}$. The equality of the mean real rates is rejected at the 1 percent level when the CPI is used to calculate the ex post real rate, but not when the WPI is used. However, when the time variables are added to the information set in the tests of line 1.2, we now see very strong rejections of the equality of real rates in both the WPI and CPI results.

$\overline{7}$ See Mishkin (1981). 


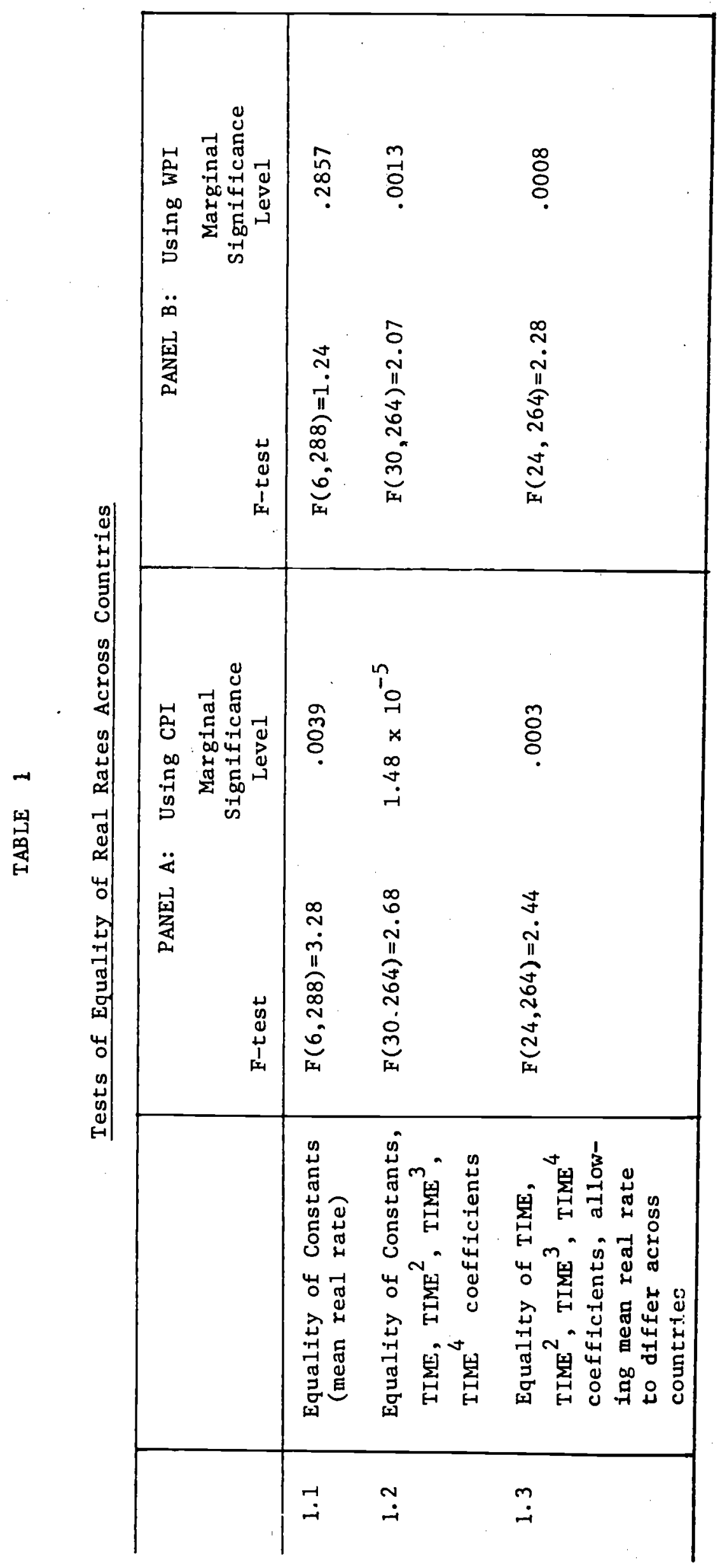


Even though real rates are not equalized across countries, it is possible that they have a different mean, but move similarly over time. This proposition is tested in line 1.3 , where the information set has the same variables as in line 1.2. Here only the coefficients of the time variables are tested for equality, while the mean real rates across countries are allowed to differ by not constraining the equality of the constant terms. Here the rejections continue to be strong, indicating that real rates in different countries do have dissimilar movements. 8

More information on why the equality of real rates is rejected in Table 1 can be obtained from bilateral tests of the equality of real rates. Table 2 reports the F-statistics for the bilateral tests that correspond to the joint tests in Table 1. As discussed in Section II, a1though twentyone different bilateral tests are reported in each cell of the table, note that only six of these can be independent. Table 2 tells the following story. The hypothesis that real rates are equal in the United States, Canada and the United Kingdom cannot be rejected. When France, Germany, the Netherlands and Switzerland are included in the bilateral comparisons, significant rejections of the equality of real rates now occur, both with each other and

${ }^{8}$ As is pointed out in Mishkin (1982), the French data and real rate est1mates are somewhat peculiar. We might suspect then that France alone is the source of the rejections of real rate equality. To check out this suspicion, the equality of real rates was tested with France excluded and the rejections were still strong. The 1.2 test using CPI data was $\mathrm{F}(25,264)=2.63$ with a marginal significance level of $7.4 \times 10^{-5}$, while for the WPI, $F(25,264)=2.11$ with a narginal significance level of .0021 . 


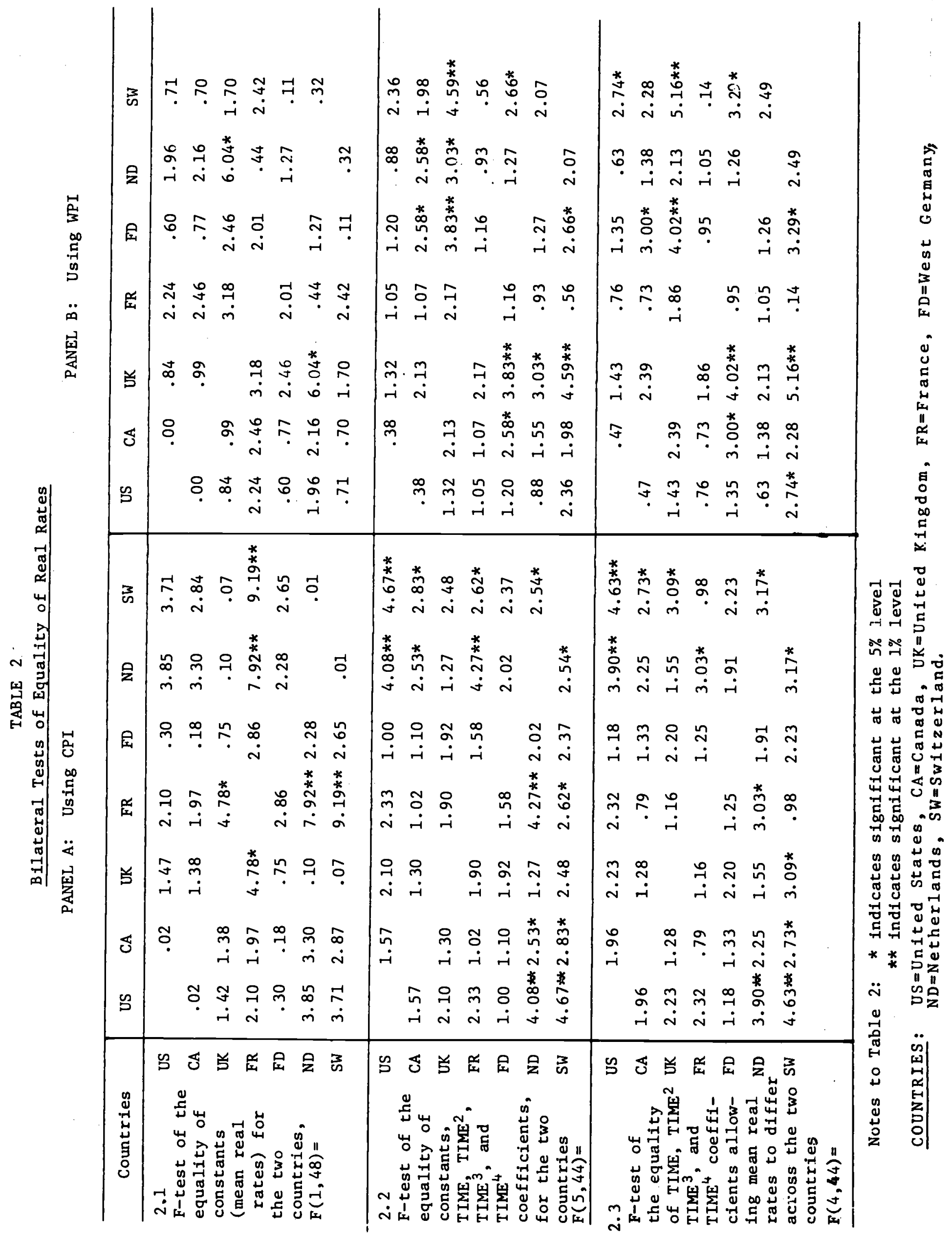


and with the first group of countries. One interesting colncidence found In Mishkin (1982) that might help us find an explanation for this phenomenon Is that the countries which lead to rejections of the equality of real rates are also the countries that display a stronger positive correlation between nominal interest rates and real rates and a weaker Fisher effect.

A comparison between the bilateral test results in Table 2 and the foint tests in Table 1 raises an Important point. Restricting your attention to a set of bilateral tests where the comparison is always between the United States and other countries can lead to an incorrect interpretation of the results. For example, In the 2.1 In Panel A and 2.2 tests in Panel B, there are no bilateral rejections of the equality of real rates in the United States and those in other countries. Th1s might lead an investigator to conclude that we cannot reject the equality of real rates across countries. However, the corresponding test results in Table 1 indicate that jointly we can strongly reject the equality of the U.S. real rate with those from the other six countrins.

This 1llustrates the value of conducting multi-country tests fointly as well as bilaterally. First, as noted In Mishkin(1982), Jolnt tests are often more powerful than single equation tests. Second, a different impression of the results can occur depending on the set of bilateral combinations studied. For example, a less favorable impression of the null hypothesis would be obtained by looking at the bilateral combinations involving France in the Panel A, 2.1 tests or those Involving Germany in the Panel B, 2.2 testa. This problem of course does not arise with the folnt tests.

Ths basic finding of this paper is that the equality of real rates across countries can be significantly rejected statistically. But it is always important to ask not only whether a rejection is statistically significant, but whether it is economically significant as well. This appears to be the 
case as seen in Figure 1 which plots, for the sample period used here, the estimates of the real rate differentials from the U.S. of the six other OECD countries; these have been obtained from Mishkin (1982). (Note that real rate differentials for other pairs of countries are just the distance between the differentials in Figure 1). Real rate differentials are often very sizable, over ten percentage points or more.

The rejections of the equality of real rates in Table 1 and 2 also provide some useful information on some of the basic parity conditions in the international economics literature. Roll (1979) has noted that 1) interest parity, 2) an ex-ante version of relative purchasing power parity (PPP), and 3) the unbiasedness of the forward rate as a predictor of the spot exchange rate are linked to the proposition that real rates are equal across countries. Denoting the $\log$ of the spot exchange rate and one-period ahead forward rate for country $j$ relative to country $i$ given at time $t-1$ as $s_{t-1}^{j}$ and $t-1 E_{t}^{j}$, respectively, the interest parity condition (1P) is:

$$
i_{t}^{j}-i_{t}^{i}={ }_{t-1} f_{t}^{j}-s_{t-1}^{j}
$$

The ex-ante version of relative PPP is: ${ }^{9}$

$$
E\left(\pi_{t}^{j}-\pi_{t}^{i}-\left.\left(s_{t}^{j}-s_{t-1}^{j}\right)\right|_{t-1}\right)=0
$$

and the unbiasedness of forward rate forecasts

$$
t-1 f_{t}^{j}=E\left(s_{t}^{j} \mid \phi_{t-1}\right)
$$

${ }^{9}$ This is a weaker condition than the usual relative PPP condition, because it will be satisfied even if the $\mathrm{log}$ of the real exchange rate follows a random walk. Thus, findings such as Frenkel's (1981b) rejecting PPP but finding that the deviations follow a random walk would be consistent with equation ( 20$)$. However, evidence discussed latter suggests that even ex ante relative PPP is violated. 


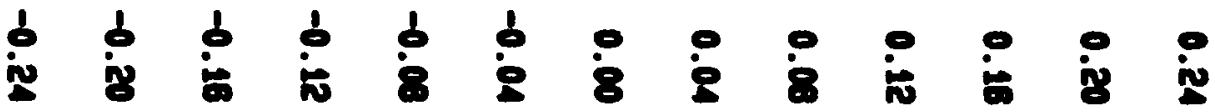

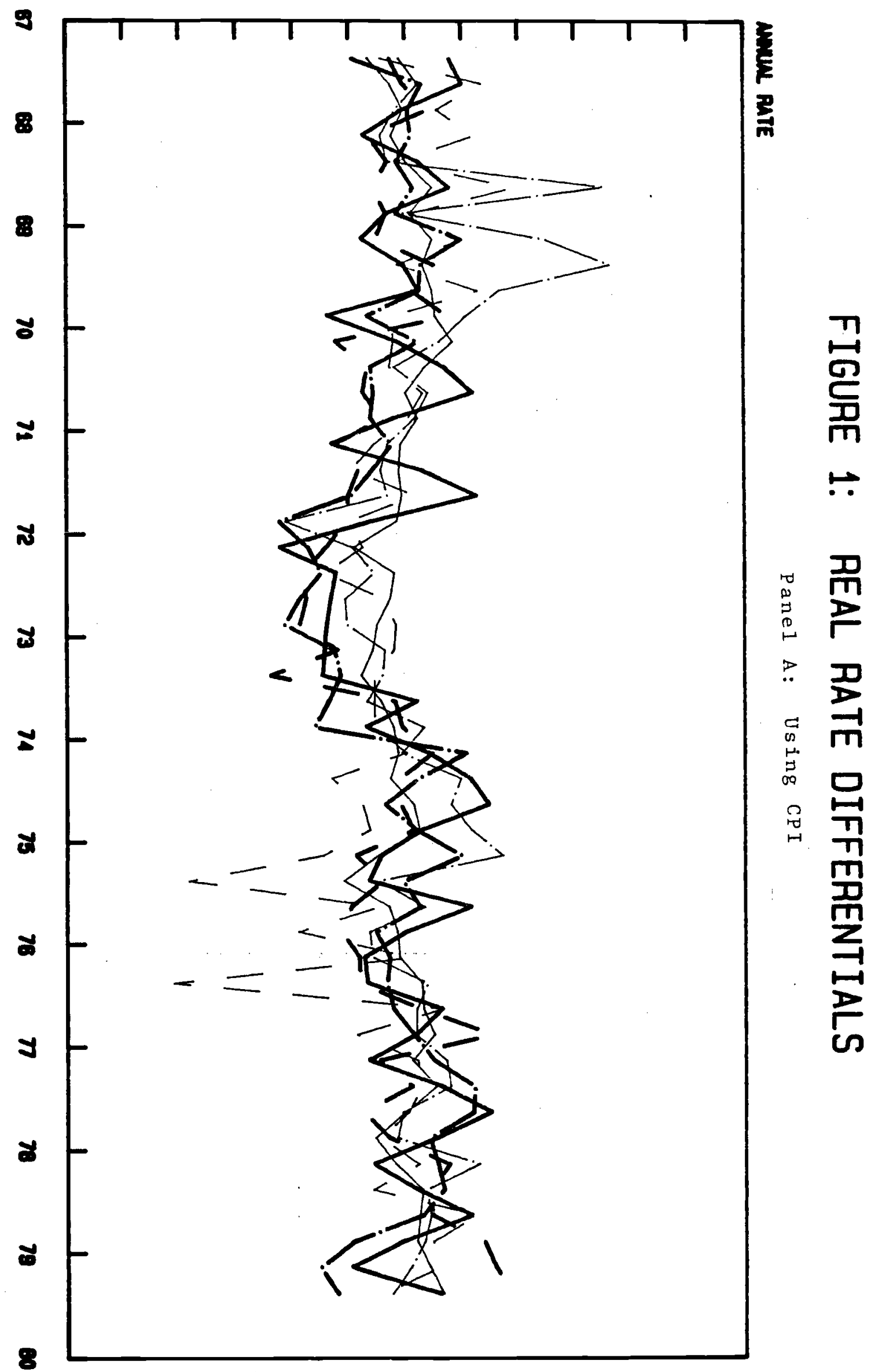




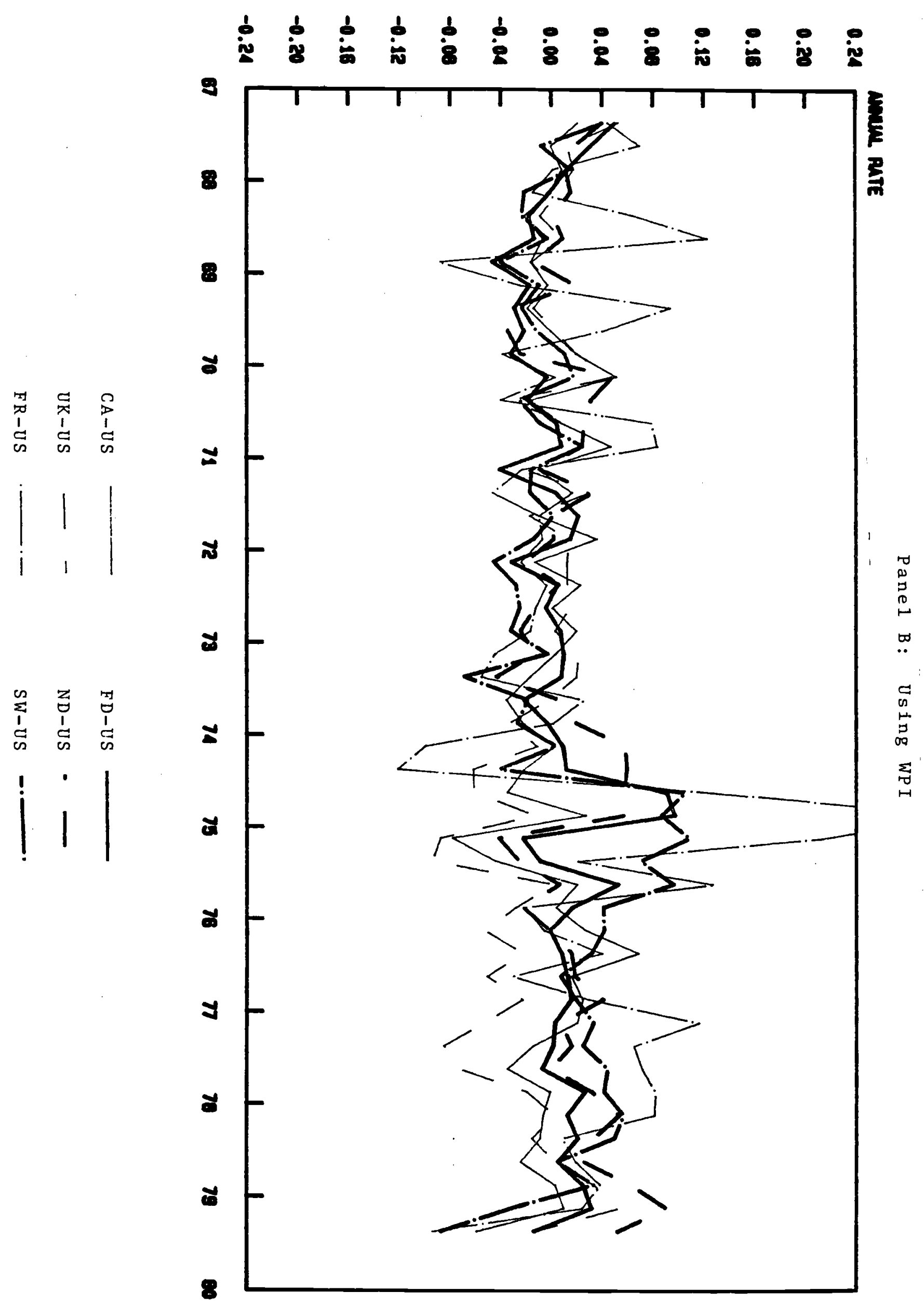


Combining (19) and (21) we obtain the uncovered interest parity condition (UIP), which is also known as the Fisher-open hypothesis: i.e.

$$
E\left(i_{t}^{j}-i_{t}^{i}-\left(s_{t}^{j}-s_{t-1}^{j}\right) \mid \phi_{t-1}\right)=0
$$

Subtracting (21) from (22) we have

$$
E\left(\operatorname{eprr}_{t}^{j}-\operatorname{eprr}_{t}^{i} \mid \phi_{t-1}\right)=0=\operatorname{rr}_{t}^{j}-\operatorname{rr}_{t}^{i}
$$

which is the condition or the equality of real rates.

As the above derivation shows, the rejection of the equality of real rates found in Tables 1 and 2 can arise from the breakdown of any of the conditions in $(19)-(22) \cdot{ }^{10}$ Frenkel and Levich $(1975,1977)$ and McCormick (1979) have shown that deviations from the interest parity are quite small in the euro currency market. Indeed, since interest parity is a pure arbitrage condition for euro rates, there is some suspicion that many of the deviations may be the result of data problems. ${ }^{11}$ Thus, the tests that follow focus on the other conditions .

Table 3 conducts tests corresponding to those in 1.2 of Table 1 of uncovered interest parity and ex-ante relative PPP, which together imply the equality of real rates. The uncovered interest parity condition in (22) implies that $\delta^{j}=0$ in the following regressions:

$\overline{10}$ Note that if the deviation from one of those conditions is exactly offset by a deviation from one of the others, real rates could still be equal. But since this is extremely unlikely, it is reasonable to view a breakdown in one of these conditions as leading to a violation of real rate equality.

${ }^{11}$ For example, conversations with Harris Bank personnel indicates that the timing of the euro rate data on the Harris tape can differ by up to an hour from that of the forward premium. This would lead to spurious deviations from interest parity. 


\section{TABLE 3}

Tests of Uncovered Interest Parity (UIP) and Ex Ante Relative Purchasing Power Parity (PPP)

PANEL A: Using CPI

Margina1

F-test

Test of

3.1 UIP

3.2 Test of Ex-Ante Relative PPP

Joint

3.3 Test of

UIP

and

Ex-Añte

Relative PPP
PANEL B: Using WPI

Margina1

F-test Significance Level

\begin{tabular}{|c|c|c|c|}
\hline$F(30,264)=.84$ & .7046 & $F(30,264)=.84$ & .7046 \\
\hline$F(30,264)=1.10$ & .3363 & $F(30,264)=.88$ & .6512 \\
\hline$F(60,528)=2.12$ & $6.88 \times 10^{-6}$ & $F(60,528)=1.45$ & .0198 \\
\hline
\end{tabular}


(24) $\quad i_{t}^{j}-i_{t}^{i}-\left(s_{t}^{j}-s_{t-1}^{j}\right)=x_{t-1} \delta^{j}+n_{t}$

where

$n_{t}=$ error term with the property $E\left(n_{t} \mid \phi_{t-1}\right)=0$ under the nul1. 12

Line 3.1 of Table 3 tests jointly $\delta^{j}=0$ in the six independent bilateral regressions where $x_{t-1}$ includes the constant term and the four time variables. Line 3.2 conducts the same test for ex-ante relative PPP of $\gamma^{j}=0$ in the six independent bilateral regressions:

$$
\pi_{t}^{j}-\pi_{t}^{i}-\left(s_{t}-s_{t-1}\right)=x_{t-1} \gamma^{j}+w_{t}
$$

where

$$
\omega_{t}=\text { error term with the property } E_{t}\left(\omega_{t} \mid \phi_{t-1}\right)=0 \text { under the null. }
$$

Neither ex ante relative PPP nor uncovered interest parity (UIP) are rejected at the 5 percent level in these tests. However, when these hypotheses are tested jointly in Line 3.3, they are rejected, and especially strongly in the $\mathrm{CPI}$ results.

At first glance the findings above are surprising. When the UIP and PPP conditions are implicitly tested together, as in tests of the equality of real rates in Table 1 , or when tested jointly as in Table 3, they are rejected. Yet when these conditions are tested independently, they are not rejected. What explains this phenomenon?

\footnotetext{
12 Under the null the $n_{t}$ and the $\omega_{t}$ error terms are as defined in equations (26) and (27). Rationality of expectations then clearly implies that $E\left(n_{t} \mid \phi_{t-1}\right)=E\left(\omega_{t} \mid \phi_{t-1}\right)=0$.
} 
The answer to this puzzle comes from investigating the error terms of the regressions above. Taking expectations conditional on the available information set $\phi_{t-1}$ of (24) and (25) and subtracting them from their respective equations, the error terms are seen to be: ${ }^{13}$

$$
\begin{aligned}
& n_{t}=-\left[s_{t}^{j}-E\left(s_{t}^{j} \mid \phi_{t-1}\right)\right] \\
& \omega_{t}=\left[\pi_{t}^{j}-\pi_{t}^{i}-E\left(\pi_{t}^{j}-\pi_{t}^{i} \mid \phi_{t-1}\right)\right]-\left[s_{t}^{j}-E\left(s_{t}^{j} \mid \phi_{t-1}\right)\right]
\end{aligned}
$$

I.e., the error term in the UIP regression is minus the forecast error of the spot rate, while the error term in the PPP regression is the forecast error of the inflation differential minus the forecast error of the spot rate. Frenkel and Mussa (1980) have documented that the spot exchange rate is highly volatile and is apparently quite hard to predict. On the other hand, inflation rates are substantially less volatile. The forecast error of the spot rate should then have a large variance which would be substantially greater than the variance of the forecast error of the inflation differential. This would imply that the variance of $n$ and $w$ would be large and thus independent tests of (24) and (25) would have low power and would be unlikely to reject even if the null hypothesis were untrue. On the other hand the contemporaneous correlation of $n$ and $\omega$ for the same bilateral combination should

$1{ }^{13}$ The derivations of the error terms are done here under the null hypotheses. If the nulls are false, then an additional term of $P\left[i_{t}^{j}-i_{t}^{i}-\left(s_{t}^{j}-s_{t-i}^{j}\right)\right.$ - $\left.E\left(i_{t}^{j}-i_{t}^{i}-\left(s_{t}^{j}-s_{t-1}^{j}\right) \mid \phi_{t-1}\right) \mid x_{t-1}\right]$ should be added to the right-hand side of the $n_{t}$-equation (26) and an additional term of $P\left[\pi_{t}^{j}-\pi_{t}^{i}-\left(s_{t}^{j}-s_{t-1}^{j}\right)\right.$ $\left.-E\left(\pi_{t}^{j}-\pi_{t}^{i}-\left(s_{t}^{j}-s_{t-1}^{j}\right) \mid \phi_{t-1}\right) \mid x_{t-1}\right]$ should be added to the right hand side of the $\omega_{\text {- }}$ - equation (27). The basic point made here is not altered by these addtional terms. 
be highly positive ${ }^{14}$ and thus when (24) and (25) are tested jointly

properly allowing for the covariance of their error terms, the test should have greater power and be more likely to reject if the null hypothesis were untrue. The evidence is consistent with the above story: the correlation of the contemporaneous $\hat{n}$ and $\hat{\omega}$ for the same bilateral combination is always greater than .9 , and the UIP and PPP conditions are jointly rejected although they are never rejected when tested independently.

The ability to reject the equality of real rates in Table 1 , but not uncovered interest parity and ex-ante relative PPP individually, also is explained by the error terms in the regressions. Subtracting (25) from (24) we get the bilateral regressions that are used to test the equality of real rates across countries, and its error term equals $\eta_{t}-\omega_{t}$. Here the forecast error of the spot rate cancels out and we are left with only the forecast error of the inflation differential. By the reasoning above this error term has much smaller variance than the error term in either the UIP or PPP regressions. Hence the test of the equality of real rates will be more powerful than tests of uncovered interest parity and ex-ante PPP when conducted independent $1 \mathrm{y}$.

If the interest partity condition holds closely, then replacing the UIP condition (22) by the unbiasedness of the forward rate forecast condition

$\overline{14}$ Denoting the variance of the unexpected inflation differential as $\sigma^{2}$, the variance of the unexpected spot rate as $\sigma_{s}^{2}$, their correlation. "coefficient as $\rho$ and the ratio of their variances as $k$, then the correlation of $n$ and $\omega s \pi$ is $1-\rho_{k}$. It is easy to show that the minimum $\sqrt{1+k^{2}-2 \rho_{s \pi} k}$ correlation occurs when $\quad \rho_{s \pi}=k$ and it equals $\sqrt{1-k^{2}}$. When $k$ is sma11, this minimum correlation is necessarily highly positive. 
in (21) should have no appreciable effect on the test results. ${ }^{15}$ This is the finding in Table 4 which conducts tests where $s_{t}^{j}-t_{t-1} f_{t}^{j}$ replaces $i_{t}^{j}-i_{t}^{i}-\left(s_{t}^{j}-s_{t-1}^{j}\right)$ in (24). The test statistics in Table 4 are almost identical to those in Table 3, never differing by more than 2 percent. This illustrates that results from uncovered interest parity tests can be used to make inferences about the unbiasedness of forward rate forecasts and the potential existence of risk premiums in the forward rate market. This is useful information because frequently data is available to test uncovered interest parity, as in Cumby and Obstfeld (1981), but is not as readily available to test the unbiasedness of the forward rate forecasts.

Because of the potential non-normalities of error terms in the fixed exchange rate period -- i.e., this is the Peso problem discussed by Krasker (1980) -- the tests on the equality of real rates, the unbiasedness of forward rate forecasts and ex-ante relative PPP for the flexible exchange rate period from 1973-III to 1979-II are reported in Table 5. The tests of uncovered interest parity for this sample period are not reported on here because, as expected, the tests statistics are very close to those for the unbiasedness of forward rate forecasts. Note that $\mathrm{X}_{t-1}$ again includes the constant term and the four time trend variables in these tests.

\footnotetext{
${ }^{15}$ Note that when tests of interest parity are conducted the same way the tests of the uncovered interest parity are conducted in the text, a strong rejection occurs: $F(30,264)=5.12$ with a marginal significance level of $6.47 \times 10^{-14}$. However, the deviations from interest parity although they produce a statistically significant rejection, are quite small. In the seven countries, the mean deviation from interest parity (using quarterly rates) range from .02 to .06 percent; and the standard deviations range from .05 percent to .. 18 percent. As the comparison of Table 3 and 4 indicate, although the rejection of interest parity is statistically significant, it is not economically significant. Of course, even the statistical rejections are probably spurious because of the data problems described in the previous footnote, and the fact that Harris Bank personnel indicate that they quote euro rates as if interest parity held perfectly.
} 


\section{TABLE 4}

Tests of Unbiasedness of Forward Rate Forecasts and Ex Ante Relative Purchasing Power Parity

\begin{tabular}{|c|c|c|c|c|}
\hline \multirow[b]{2}{*}{$\begin{array}{l}\text { Test of } \\
\text { Unbiasedness } \\
\text { of forward } \\
\text { rate } \\
\text { forecasts }\end{array}$} & \multicolumn{2}{|c|}{$\begin{array}{rc}\text { PANEL A: } & \text { Using CPI } \\
& \text { Marginal } \\
\text { F-test } & \text { Significance Level }\end{array}$} & \multicolumn{2}{|c|}{$\begin{array}{cc}\text { PANEL B: } & \text { Using WPI } \\
& \text { Marginal } \\
\text { F-test } & \text { Significance Level }\end{array}$} \\
\hline & $F(30,264)=.85$ & .7016 & $F(30,264)=.85$ & .7016 \\
\hline $\begin{array}{l}\text { Test of } \\
\text { Ex-Ante } \\
\text { Relative } \\
\quad \text { PPP }\end{array}$ & $F(30,264)=1.10$ & .3363 & $F(30,264)=.88$ & .6512 \\
\hline $\begin{array}{l}\text { Joint } \\
\text { Test of } \\
\text { Unbiasedness } \\
\text { of forward } \\
\text { rate } \\
\text { forecasts } \\
\text { and Ex Ante } \\
\text { Relative PPP }\end{array}$ & $F(60,528)=2 \cdot 10$ & $8.73 \times 10^{-6}$ & $F(60,528)=1.47$ & .0152 \\
\hline
\end{tabular}


TABLE 5

Flexible Exchange Rate Period: 1973-III to 1979-II

Tests of Unbiasedness of Forward Rate Forecasts,

Ex Ante Relative Purchasing Power Parity and the Equality of Real Rates Across Countries

\begin{tabular}{|c|c|c|c|c|}
\hline \multirow{2}{*}{. } & \multicolumn{2}{|c|}{ PANEL A: Using CPI } & \multicolumn{2}{|c|}{ PANEL B: Using WPI } \\
\hline & F-test & Bignificance Leve1 & F-test & Significance Level \\
\hline $\begin{array}{l}\text { Test of } \\
\text { Unbiasedness } \\
\text { of forward } \\
\text { rate } \\
\text { forecasts }\end{array}$ & $F(30,114)=1.71$ & .0229 & $F(30,114)=1.71$ & .0229 \\
\hline $\begin{array}{l}\text { Test of } \\
\text { Ex Ante } \\
\text { Relative } \\
\text { PPP }\end{array}$ & $F(30,114)=1.61$ & .0395 & $F(30,114)=1.03$ & .4427 \\
\hline $\begin{array}{l}\text { Joint } \\
\text { Test of } \\
\text { Unbiasedness } \\
\text { of forward } \\
\text { rate } \\
\text { forecasts } \\
\text { and Ex Ante } \\
\text { Relative PPP }\end{array}$ & $F(60,228)=2.78$ & $2.52 \times 10^{-8}$ & $F(60,228)=5.64$ & $6.09 \times 10^{-22}$ \\
\hline $\begin{array}{l}\text { Test of } \\
\text { equality } \\
\text { of real } \\
\text { rates } \\
\text { across } \\
\text { countries }\end{array}$ & $F(30,1.14)=2.39$ & .0005 & $F(30,114)=5.32$ & $3.26 \times 10^{-11}$ \\
\hline
\end{tabular}


The general flavor of these results is similar to that found for the larger sample period. Tests of the equality of real rates or joint tests of ex-ante relative PPP and the unbiasedness of the forward rate forecasts yield much stronger rejections than independent tests of ex-ante relative PPP and the unbiasedness of forward rate forecasts. However, now we do see rejections of the unbiasedness of the forward rate forecasts at the 5 percent, although not at the 1 percent level, and a rejection of ex-ante relative PPP for the CPI at the 5 percent level. The rejections of these hypotheses jointly is also stronger and is especially so using the WPI where the marginal significance level is below $10^{-20}$. The equality of real rates, as expected from the above results, is also rejected quite strongly using both the CPI and WPI. 
IV. CONCLUSIONS

The empirical evidence in this paper strongly rejects the hypothesis of the equality of real euro rates across countries. The joint hypotheses of uncovered interest parity and ex ante relative PPP, or the unbiasedness of forward rate forecasts and ex-ante relative PPP, are also strongly rejected. Yet independent tests of uncovered interest parity, the unbiasedness of forward rate forecasts and ex ante relative PPP yield few rejections and high marginal significance levels.

As these findings consistent with other empirical results in the literature? The answer is yes. Roll (1979) also finds that he frequently cannot reject the null hypothesis of ex-ante relative PPP, and, as argued here, this is likely to be the result of the low power of the tests. If more powerful statistical procedures are used to test this hypothesis, as in Cumby and Obstfeld (1982), we do see significant rejections. Similarly, tests of the unbiasedness of forward rate forecasts or of uncovered interest parity do not frequently reject the null hypothesis when tests of low statistical power are used as in Frenkel (1981b). However, more powerful statistical tests, such as in Hansen and Hodrick $(1980,1981)$ and Cumby and Obstfeld $(1981,1982)$, do reject these null hypotheses. Hodrick (1980) conducts bilateral tests of the equality of real rates in the United States versus other countries, finds the evidence mixed, and concludes that the results are reasonably supportive of the nul1 hypothesis. ${ }^{16}$ The U.S. bilateral results here are

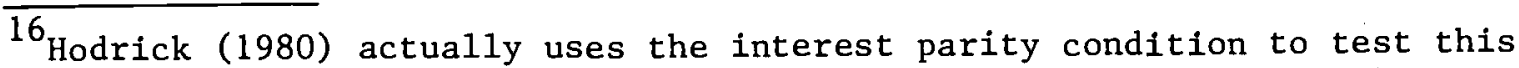
hypothesis using forward and spot rates rather than euro rates, but as shown above this would have no appreciable effect on the results.
} 
somewhat similar to Hodrick's, but as discussed above, focusing on these U.S. bilateral comparisons alone can be misleading. More powerful joint tests here strongly reject the equality of real rates and this is consistent with Cumby and Obstfeld's (1982) tests which also strongly reject this proposition.

How should we interpret this evidence? It is important to state that the rejection of the equality of real rates, uncovered interest parity, the unbiasedness of forward rate forecasts or ex-ante relative PPP does not imply the existence of irrationality or unexploited profit opportunities. In a world with risk averse economic agents, risk premiums in the forward exchange market can easily exist, differ across countries and undergo variation over time. Furthermore, transaction costs and non-substitutability of different countries' goods can imply the violation of purchasing power parity conditions even when there are no unexploited profit opportunities. ${ }^{17}$ Finally, problems with both the CPI and WPI price indices which are often subject to government intervention, both explicitly through wage and price controls and through more subtle manipulation of the construction of the indices themselves, can lead to a less favorable view of purchasing power parity than is really. warranted.

The evidence then suggests that it is worth studying open economy models which allow: 1) domestic real rates to differ from world rates, 2) time varying risk premiums in the forward market or 3) deviations from ex ante relative purchasing power parity. The evidence also leaves open the

\footnotetext{
$\overline{17}$ That marginal tax rates on euro interest payments can differ across countries might also be a factor in differing real rates.
} 
possibility for policy makers to exert some control over their domestic real rate relative to those in the rest of the world. However, the evidence does not rule out that there is a tendency for real rates across countries to equalize over time, and this is an important topic for further research. 
References

Abel, A. and Mishkin, F.S. (1983) "An Integrated View of Test of Tests Rationality, Market Efficiency and the Short-Run Neutrality of Monetary Policy," Journal of Monetary Economics, forthcoming.

Bilson, J.F.O. (1978), "Rational Expectations and the Exchange Rate," in The Economics of Exchange Rates: Selected Studies, edited by J.A. Frenkel and H.G. Johnson. (Addison-Wesley: Reading, Mass.)

Cumby, R.E. and M. Obstfeld, (1981), "A Note on Exchange-Rate Expectations and Nominal Interest Differentials: A Test of the Fisher Hypothesis." Journal of Finance 36 (June 1981): 697-704.

, (1982), "International Interest-Rate and Price-Level Linkage Under Flexible Exchange Rates: A Review of Recent Evidence," National Bureau of Economic REsearch (January).

Dornbusch, R. (1976) "Expectations and Exchange Rate Dynamics," Journal of Political Economy 84 (December): 1161-76.

Feldstein, M. (1982), "Domestic Savings and International Capital Movements in the Long-Run and the Short-Run," NBER Working Paper 非947 (July).

Fisher, I., (1930) The Theory of Interest (New York: MacMillan).

Frenka1, J.A. (1979), "On the Mark: The Theory of Floating Exchange Rates Based on Real Rate Differentials," American Economic Review 69 (September): .610-22.

Frenkel, J.A. (1976), "A Monetary Approach to the Exchange Rate: Doctrinal Aspects and Empirical Evidence," Scandinavian Journal of Economics 78 (May) : 200-24.

, (1981), "Flexible Exchange Rates, Prices, and the Role of News: Lessons from the 1970's," Journal of Political Economy 89 (August): 667-705.

Frenkel, J.A. and R.M. Levich, (1975), "Covered Interest Arbitrage: Unexploited Profits?" Journal of Political Economy 83 (April): 325-38.

, (1977), "Transactions Costs and Interest

Arbitrage: Tranquil Versus Turbulent Periods," Journal of Political Economy 85 (December): 1209-26.

and M. Mussa, (1980). "The Efficiency of the Foreign Exchange Market and Measures of Turbulence," The American Economic Review 70 (May): 374-81. 
References (continued)

Hansen, L.P. and R.J. Hodrick, (1980), "Forward Exchange Rates as Optimal Predictors of Future Spot Rates: An Econometric Analysis," Journal of Political Economy 88 (October): 829-53.

, (1981), "Risk Averse Speculation in the Foreign Exchange Market: An Econometric Analysis," Working Paper, GSIA, Carnegie-Mellon University.

Hodrick, R. J., (1980), "Some Evidence on the Equality of Expected Real Rates Across Countries," Working Paper 非-79-80, GSIA, Carnegie-Mellon University (January).

Krasker, W.S., (1980), "The Peso Problem in Testing Efficiency of Forward Exchange Markets," Journal of Monetary Economics 6: 269-76.

McCormick, F., (1979), "Covered Interest Arbitrage: Unexploited Profits? Comment," Journal of Political Economy 87 (April): 411-17.

Mishkin, F.S., (1981), "The Real Interest Rate: An Empirical Investigation," The Cost and Consequences of Inflation, Carnegie-Rochester Conference Series on Public Policy, vol. 15, (Autumn): 151-200. ,(1982), "The Real Interest Rate: A Multi-Country Empirical Study," Northwestern University, (November).

Roll, R., (1979), "Violation of Purchasing Power and their Implications for Efficient International Commodity Markets," in Sarnat and Szego, eds., International Finance and Trade, vol. 1, (Ballinger): 133-176. 